\title{
Microwave-Assisted Carbochlorination Recovery of Indium Process of Dynamic Simulation Based on Multi-Field Coupling
}

Jie Guan ${ }^{1,2^{*}}$, Meiling Liu ${ }^{1}$, Ruijing $\mathrm{Su}^{1,2^{*}}$, Yaoguang Guo ${ }^{1}$, Dongxue $\mathrm{Xiao}^{3}$, Liu $\mathrm{Hu}^{4^{*}}$, Yingshun $\mathrm{Li}^{5}$, Yanan $\mathrm{Zhu}^{6}$, Weixing $\mathrm{Gu}^{7}$, Congbing $\mathrm{Ni}^{8}$ and Zhanhu Guo

The microwave-assisted carbochlorination process of indium trichloride $\left(\mathrm{InCl}_{3}\right)$ recovery in the microwave reactor cavity of the laboratory has been obtained by the Finite Element Method (FEM) software of COMSOL Multiphysics. Base on the multi-field coupling simulation, analysis was conducted on the factors affecting its process. Firstly, combined microwave heating process, Computational Fluid Dynamics and mass transport process, a mathematical-physical model coupled of 4 physics fields, which include radio frequency, heat transfer, mass transport and flow field, has been established. Then further researches focus on the electric field of the cavity. It is concluded heat source of microwave heating process and chloridizing reaction velocity, which indicate that the research model can accurately describe the influence on the process of indium recovery from the microwave input power, hydrogen chloride $(\mathrm{HCl})$ flow rate and sample location.

Keywords: Multi-field coupling; Numerical simulation; Microwave-heating; Carbochlorination; $\mathrm{InCl}_{3}$

Received 24 May 2019, Accepted 23 August 2019

DOI: $10.30919 /$ esee8c322

\section{Introduction}

The rare-metal indium has excellent physico-chemical properties and is widely used in important fields such as communications, industry and military. ${ }^{1,2}$ However, it is estimated that the stock of indium is only 16,000 tons and it mainly associates with sphalerite and other ores in nature in an extremely low content, about 1-100 ppm. ${ }^{3,4}$

Nevertheless, more than $70 \%$ of indium is used annually to produce liquid crystal display (LCD) panels worldwide with the number

${ }^{1}$ School of Environmental and Materials Engineering, Shanghai Polytechnic University, Shanghai 201209, China

${ }^{2}$ Research Center of Resource Recycling Science and Engineering, Shanghai Polytechnic University, Shanghai 201209, China

${ }^{3}$ East China Sea Fisheries Research Institute, Chinese Academy of Fishery Sciences, Shanghai 200090, China

${ }^{4}$ Key Laboratory of Materials Processing and Mold (Zhengzhou University), Ministry of Education; National Engineering Research Center for Advanced Polymer Processing Technology, Zhengzhou University, Zhengzhou, Henan 450002, China

${ }^{5}$ Shanghai Xin Jinqiao Environmental Protection Co., Ltd., Shanghai 201201, China

${ }^{6}$ Shanghai Pudong Shuguang Research Center for High Environmental Treatment Technologies, Shanghai 20209, China

'Shanghai Julang Environment al Protection Co., Ltd. Shanghai 201712, China

${ }^{8}$ Shanghai Kaihong Environment al Protection Co., Ltd. Shanghai 201209, China

'Integrated Composites Laboratory (ICL), Department of Chemical \& Bimolecular Engineering, University of Tennessee, Knoxville, TN 37996, USA

*E-mail: guanjie@sspu.edu.cn; rjsu@sspu.edu.cn; liuhu@zzu.edu.cn of Indium Tin Oxide (ITO) films (stannic oxide $\left(\mathrm{SnO}_{2}\right)$ : Indium oxide $\left(\mathrm{In}_{2} \mathrm{O}_{3}\right)=1$ : 9) increasing. ${ }^{1,5}$ The indium in waste LCD has a good recovery value for their short life, fast update and higher content that from 100 to $400 \mathrm{ppm}^{6}$. At the same time, a large amount of waste LCD productions also provide an important way to regenerate indium.

Hydrometallurgy, especially the acid leaching method, is used the most in the process of recovering indium. ${ }^{8-11}$ With the development of science and technology, more methods are carried out with oxidation, ${ }^{12}$ biology ${ }^{13}$ and microwave assisted..$^{14,15}$ In particular the microwave metallurgy has quickly drawn people's attention. The main role of microwave in metallurgical engineering is to assist extraction, leaching, digestion, synthesis, carbon heat and so on. ${ }^{14}$

Since chlorinated indium $\left(\mathrm{InCl}_{3}\right)$ is an important raw material for the production of ITO, it is feasible to recover metal indium by microwave-assisted carbothermal chlorination. Guan et $a .^{16-18}$ have researched alkali-soluble LCD glass substrate powder removed silicon and aluminum, improving the chlorination effect of the indium recovery. $\mathrm{InCl}_{3}$ can be evaporated at a relatively low temperature and condensed in a cooler zone, and indium chloride can be selectively recovered. Furthermore, this process is suitable for industrial large-scale application with lower costs. Ma et al. ${ }^{19}$ reported that the recovery of indium from LCD panel reached $98.02 \%$ in a rough vacuum condition via chloridizing metallurgy process with hydrogen chloride $(\mathrm{HCl})$ as chlorinating agent provided by the pyrogenic decomposition of ammonium chloride $\left(\mathrm{NH}_{4} \mathrm{Cl}\right)$. However, this vacuum condition is difficult to control.

In spite of the relevant theoretical support, achieving effectively heat and mass transfer plays an important role in recovery rate increasement under the multi-field coupling. For lack of related researches, it is necessary to do further study on the effect of radio frequency (RF)-temperature rise-fluid-chemical reaction in indium recovery process. Based on the previous studies and the COMSOL 
Multiphysics software finite element method, this paper purposes to analyze numerically the indium recovery process with microwave carbothermal assisted and to explore the effect of microwave input power, gas flow and sample position, so as to optimize the cavity structure and provide a reference to the design of reaction system.

\section{RF-temperature rise -fluid-chemical reaction coupled physical model}

In this study, control equation is composed of microwave transmission control equation, heat exchange control equation, fluid dynamics control equation, material transfer control equation. ${ }^{1620}$

The parameter value in microwave field gives by solving the microwave transmission control equation as:

$$
\nabla \times\left(\mu_{r}^{-1} \nabla \times E\right)-k_{0}^{2} \epsilon_{r c} E=0
$$

where: $\nabla \times$ : curl calculation, $\mu_{\mathrm{r}}$ : relative dielectric constant, $\in \mathrm{rc}$ : relative permeability, E: electric field intensity, $\mathrm{V} / \mathrm{m}$.

The wave number in free space is calculated as Eq. 2.

$$
k_{0}=\omega \sqrt{\varepsilon_{0} \mu_{0}}=\frac{\omega}{c_{0}}
$$

The heat source $\mathrm{Q}$ gives by heat exchange control equation as:

$$
\begin{gathered}
\rho C_{p} \frac{\partial T}{\partial t}+\rho C_{p} u \cdot \nabla T+\nabla \cdot T=Q \\
q=-k \nabla T
\end{gathered}
$$

where $\rho$ : density of solid or fluid, $\mathrm{kg} / \mathrm{m}^{3}$. $\mathrm{C}_{\mathrm{p}}$ : heat capacity, $\mathrm{J} /(\mathrm{kg} \cdot \mathrm{K})$. $\mathrm{k}$ : heat conductivity, $\mathrm{W} /(\mathrm{m} \cdot \mathrm{K}) . u$ : heat exchange speed, $\mathrm{m} / \mathrm{s} . \nabla T$ : temperature gradient, $\mathrm{K} / \mathrm{m}$.

Meanwhile, heat source consists of two parts: microwave heat source $\mathrm{Q}_{\mathrm{e}}$ and enthalpy change of chemical reaction $\mathrm{Q}_{\mathrm{r}}$. Microwave heating is contributed by thermal impedance $\mathrm{Q}_{\mathrm{m}}$ and magnetic loss $\mathrm{Q}_{\mathrm{m} \cdot}$. These values are functionalized on the current density $J\left(\mathrm{~A} / \mathrm{m}^{2}\right)$, frequency $\omega(\mathrm{Hz})$ magnetic flux B (T) and magnetic field intensity $\mathrm{H}$ $(\mathrm{A} / \mathrm{m})$ as:

$$
\begin{gathered}
Q=\mathrm{Q}_{\mathrm{e}}+\mathrm{Q}_{\mathrm{r}} \\
Q_{r h}=\frac{1}{2} \mathrm{R}_{\mathrm{e}}(\mathrm{J} \cdot \mathrm{E}) \\
Q_{m l}=\frac{1}{2} \mathrm{R}_{\mathrm{c}}(\mathrm{i} \omega \mathrm{B} \cdot \mathrm{H})
\end{gathered}
$$

Fluid dynamics of $\mathrm{HCl}$ gas is calculated by mass continuity equation and momentum continuity equation.

$$
\begin{gathered}
\frac{\partial \rho}{\partial t}+\nabla \cdot(\rho u)=0 \\
\rho \frac{\partial u}{\partial t}+(\rho u \cdot \nabla) u=\nabla \cdot\left[-p I+\tau^{\prime}\right]+F
\end{gathered}
$$

where $\rho$ : fluid density, $\mathrm{kg} / \mathrm{m}^{3}$. t: time, s. $u$ : fluid velocity, $\mathrm{m} / \mathrm{s} . p$ : pressure, Pa. F: body force, N.

$\mathrm{HCl}$ gas reacts with the sample as:

$$
\mathrm{In}_{2} \mathrm{O}_{3}+6 \mathrm{HCl}=2 \mathrm{InCl}_{3}+3 \mathrm{H}_{2} \mathrm{O}
$$

In this chemical reaction, material transfer is controlled by:

$$
\begin{gathered}
\frac{\partial c_{i}}{\partial t}+\nabla \cdot\left(-\mathrm{D}_{\mathrm{i}} \nabla c_{i}\right)+u \cdot \nabla c_{i}=R_{i} \\
R_{i}=A_{i} \cdot \exp \left(-\frac{\mathrm{Ea}}{\mathrm{RT}}\right)
\end{gathered}
$$

where i: $\mathrm{HCl}$ or $\mathrm{InCl}_{3} \cdot \mathrm{C}_{\mathrm{i}}$ : material concentration, $\mathrm{mol} / \mathrm{m}^{3}$. $\mathrm{D}_{\mathrm{i}}$ : diffusion coefficient. $\mathrm{R}_{\mathrm{i}}$ : reaction rate. $\mathrm{A}_{\mathrm{i}}$ : pre-exponential factor. Ea: activation energy of metarial $\mathrm{i}, \mathrm{J} / \mathrm{mol}$. $R$ : gas constant. $T$ : temperature, $\mathrm{K}$.

All the relevant control equations have partial differential operators and the weak solution form describes the mathematical variables in integrals, which can effectively reduce the continuity requirements of integral variables. Upon these, the weak solution form is very suitable for solving nonlinear coupling problems in multiphysics field. Therefore, the partial differential equations of physics in COMSOL should be first transformed into the form of weak solutions and then give a solution.

Having taken into account the factors such as the convergence of the model, the time for solution and the focused variables, assumptions are made in the physical model of this study:

1) All substances are materials of the same properties and standard value, that is, the comprehensively measured performance values of density, viscosity, heat transfer coefficient and relative permittivity are exactly constant;

2) As the gas flows slowly and the density has slight impact on the reaction, it is considered that the variation of density in flow process can be neglected, which is simplified as incompressible fluid, and the flow field reaches the steady state first;

3) Since the side reactions are complicated, and the temperature control of the indium oxide recovery system can promote the production of the target product ${ }^{20}$, the side reaction in the process of indium oxide recovery is ignored and only the main reaction (10) is considered;

4) The temperature changes lead to the phase transformation in the $\mathrm{InCl}_{3}$ recovery process, but it only affects the final actual amount of recovery and does not participate in the reaction of carbothermal chlorination for indium extraction. Therefore, the phase transition problem of $\mathrm{InCl}_{3}$ at different temperatures is neglected in order to improve the convergence of the model and shorten the solution time;

5) The actual process of heat transfer is divided into: heat conduction, convection heat transfer, heat radiation. But because the sample is prepared as a mixture of carbon and indium powder, the surface emissivity is more difficult to determine. Besides, the influence of heat radiation to the outside in this experiment is less than that of heat conduction and convection heat transfer. Therefore, in this paper, only heat transfer and convection heat transfer modes are considered for the moment, and the mode of radiation heat transfer is neglected;

6) The rate equation of reaction is described by the Arrhenius equation and limited by the experiment conditions, the concentration of the reactant is neglected for the time being.

In the process of solving the physics problem, the steady statetransient-frequency domain methods are used to solve four physical fields, in which the Muitifrontal Massively Parallel sparse direct Solver (MUMPS) is used to solve the flow field, the geometrical multi-grid solver is used for the geometric multi-grid solver is used in RF, temperature and reaction field, with a V-cycle, where the multi-grid layer is 1 , the coarsening factor is 2 , and SOR vector solver is used to the pre-smoother and post-smoothed, while MUMPS solver is for coarser solver. This setting can ensure the efficiency and convergence of the solution.

\section{Calculation model}




\subsection{Research object}

The mixed powder of indium oxide and carbon is used in this sample. The microwave is input from the left port of the cavity, where a quartz tube with a metal bracket is placed, and the sample is laid on the bracket. $\mathrm{HCl}$ gas flows up from the lower port of the quartz tube, ${ }^{20}$ and reacts with the sample, generating $\mathrm{InCl}_{3}$ and outflowing with $\mathrm{HCl}$ from the upper quartz tube port, as shown in Table 1 and Fig. 1. The threedimensional solid modeling is completed by using the geometric modeling tools provided by COMSOL software. It is divided by tetrahedron mesh generation, and the second-order element of regular size is used to mesh the geometric model, while the boundary layer meshes of the fluid domain are used to obtain a discretized grid with a total of 17992 tetrahedrons, as shown in Fig. 2.

\subsection{Definite conditions and the set of physical parameters}

Appropriate boundary conditions and the initial value must be given before the definite solution of partial differential equations. The following boundary conditions have been given respectively in the experiment of the RF-temperature rise-fluid-chemical reaction coupling model.

1) Boundary conditions in RF - frequency domain physical field:

Power loading: $\mathrm{P}=1500 \mathrm{~W}$, set a rectangular port, TE 10 mode, mode phase 0 rad;

Impedance boundary: All the remaining boundaries are set as the impedance boundary. The value of impedance is set as the actual measured value of the microwave cavity shell.

2) Boundary conditions in solid-fluid heat transfer physics:

$\mathrm{HCl}$ inlet: access to room temperature $\mathrm{HCl}$ gas is the first boundary conditions with $20^{\circ} \mathrm{C}$;

$\mathrm{HCl}$ outflow: set to exit boundary where there is only convective heat transfer;

The remaining external boundary: set to the boundary conditions of natural convective heat transfer, with the heat transfer coefficient $\mathrm{h}=$ $5 \mathrm{~W} /\left(\mathrm{m}^{2} \cdot \mathrm{K}\right)$, and room temperature;

Because the metal bracket are in quartz tubes, internal boundary conditions are required to describe the effect of the bracket on the heat transfer performance in the system where the coupling flow field, geometry and density of the bracket, heat capacity, and thermal conductivity are required.

Many physics models are used in this paper, and some of the parameter settings are shown in Table 2.

3) Boundary conditions in hydrodynamic physics:

$\mathrm{HCl}$ inlet: $\mathrm{HCl}$ gas flow has been measured from a given experiment; $\mathrm{HCl}$ outflow: atmospheric pressure boundary;

As the metal bracket is in the quartz tube, it is still necessary to describe it in the flow field by internal boundaries, where the metal is simply reduced to a porous grid and set as geometry parameters;

4) Boundary conditions in the material-transfer field of chemical reaction:

$\mathrm{HCl}$ inlet: $\mathrm{HCl}$ gas concentration has been measured from for a given experiment;

$\mathrm{HCl}$ outflow: set to outflow boundary conditions;

All the initial values of the physics field can be set as the default 0 , and COMSOL will automatically judge the initial value according to the boundary conditions and obtain the self-consistent initial calculation value.

Table 1 The Size of the Geometric Model.

\begin{tabular}{ccc}
\hline Designation & Value & Units \\
\hline Height of the Microwave Cavity & 100 & $\mathrm{~mm}$ \\
Thickness of the Microwave Cavity & 58 & $\mathrm{~mm}$ \\
Radius of the Microwave cavity & 80 & $\mathrm{~mm}$ \\
Length of the Microwave Cavity & 162 & $\mathrm{~mm}$
\end{tabular}

Note: Thickness is ignored in bracket geometry modeling, but the effect of physical thickness on heat transfer is taken into account in practical calculations.

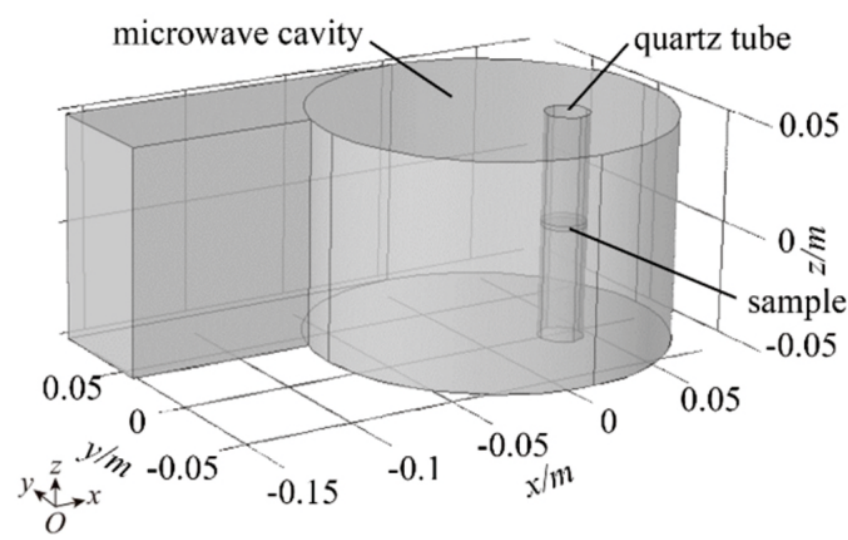

Fig. 1 Three-dimensional diagram of the geometric entity.

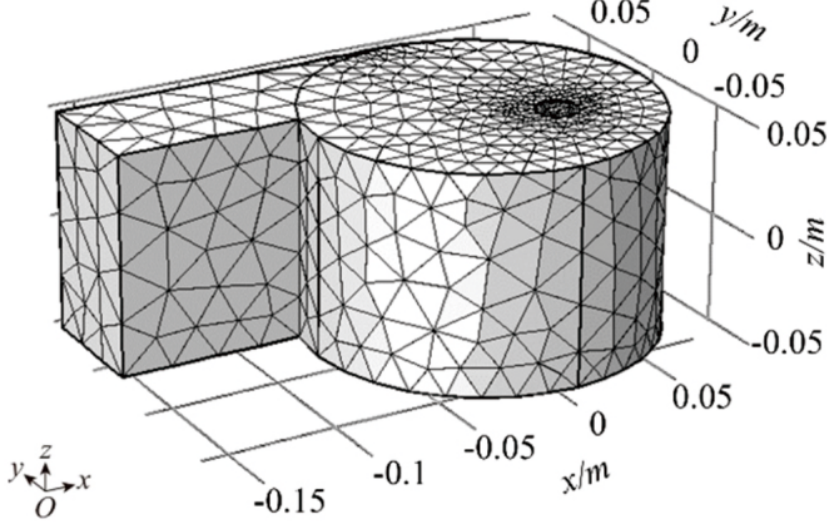

Fig. 2 Tetrahedron Meshing Diagram. 
Table 2 Physical Parameters.

\begin{tabular}{|c|c|c|}
\hline Designation & Value & Units \\
\hline Inlet flow & 100 & $\mathrm{ml} / \mathrm{min}$ \\
\hline Inlet gas temperature & 20 & ${ }^{\circ} \mathrm{C}$ \\
\hline The concentration of indium & 0 & $\mathrm{~mol} / \mathrm{L}$ \\
\hline Relative shell permeability & 1 & - \\
\hline Shell conductivity & $4.032 \times 10^{6}$ & $\mathrm{~S} / \mathrm{m}$ \\
\hline Relative shell permittivity & 1 & - \\
\hline Shell heat capacity & 475 & $\mathrm{~J} /(\mathrm{kg} \cdot \mathrm{K})$ \\
\hline Shell thermal conductivity & 44.5 & $\mathrm{~W} /(\mathrm{m} \cdot \mathrm{K})$ \\
\hline Pre-exponential factor & 537 & - \\
\hline Stent relative permittivity & 1 & - \\
\hline Bracket density & 8960 & $\mathrm{~kg} / \mathrm{m}^{3}$ \\
\hline $\mathrm{HCl}$ Concentration & 2 & $\mathrm{~mol} / \mathrm{L}$ \\
\hline Relative $\mathrm{HCl}$ permittivity & 1 & - \\
\hline $\mathrm{HCl}$ viscosity & $\mathrm{mu}(\mathrm{T})$ & \\
\hline Sample density & 650 & $\mathrm{~kg} / \mathrm{m}^{3}$ \\
\hline Relative permittivity of the sample & Epson(T) & \\
\hline Sample thermal conductivity & 0.3 & $\mathrm{~W} /(\mathrm{m} \cdot \mathrm{K})$ \\
\hline \multicolumn{3}{|l|}{ Quartz tube: } \\
\hline Heat capacity & 730 & $\mathrm{~J} /(\mathrm{kg} \cdot \mathrm{K})$ \\
\hline Conductivity & $1 \times 10^{-14}$ & $\mathrm{~S} / \mathrm{m}$ \\
\hline Density & 2210 & $\mathrm{~kg} / \mathrm{m}^{3}$ \\
\hline Relative dielectric constant & 4.2 & - \\
\hline
\end{tabular}

Note: Some physical parameters are variables that change with temperature.

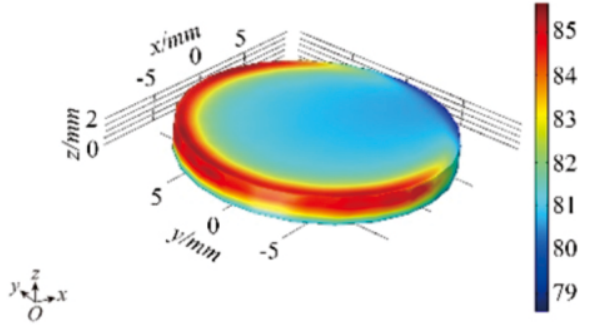

(a) $\mathrm{P}=500 \mathrm{~W}$
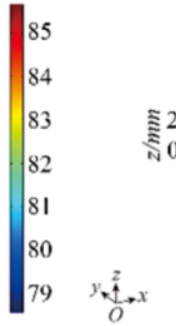

(b) $\mathrm{P}=1000 \mathrm{~W}$
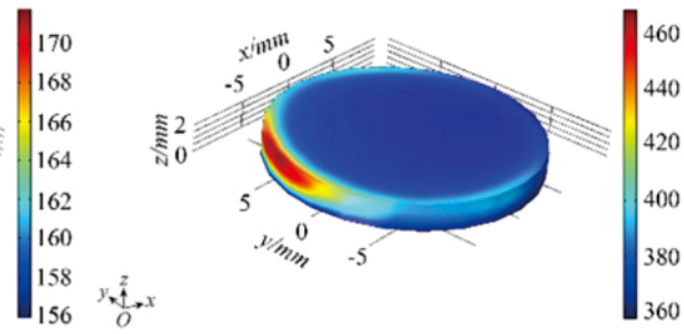

(c) $\mathrm{P}=1500 \mathrm{~W}$

Fig. 3 Temperature distribution of after 10 min of heating. 


\section{Results and discussions}

4.1 Microwave input power on the impact of temperature rise The parametric swept solver of COMSOL Multiphysics has given the solution of the recovery process at load power $500 \mathrm{~W}, 1000 \mathrm{~W}$, and $1500 \mathrm{~W}$. The temperature distributions of heating 10 minutes are shown in Fig. 3.

It can be seen that after having heated for $10 \mathrm{~min}$ the highest temperature of the sample with microwave power $500 \mathrm{~W}$ is $85{ }^{\circ} \mathrm{C}$, and the lowest temperature is $78.5^{\circ} \mathrm{C}$. The temperature difference is $6.5^{\circ} \mathrm{C}$, the area of high temperature is on the side close to microwave loading port. At power $1000 \mathrm{~W}$, the highest temperature is $172{ }^{\circ} \mathrm{C}$, and the lowest is $156{ }^{\circ} \mathrm{C}$ with a $16{ }^{\circ} \mathrm{C}$ temperature difference. The distribution trend is similar to that in Fig. 3 (a). At power $1500 \mathrm{~W}$, the highest temperature is $475{ }^{\circ} \mathrm{C}$, the lowest is $360{ }^{\circ} \mathrm{C}$, with a $115{ }^{\circ} \mathrm{C}$ temperature difference. The temperature distribution changes obviously compared

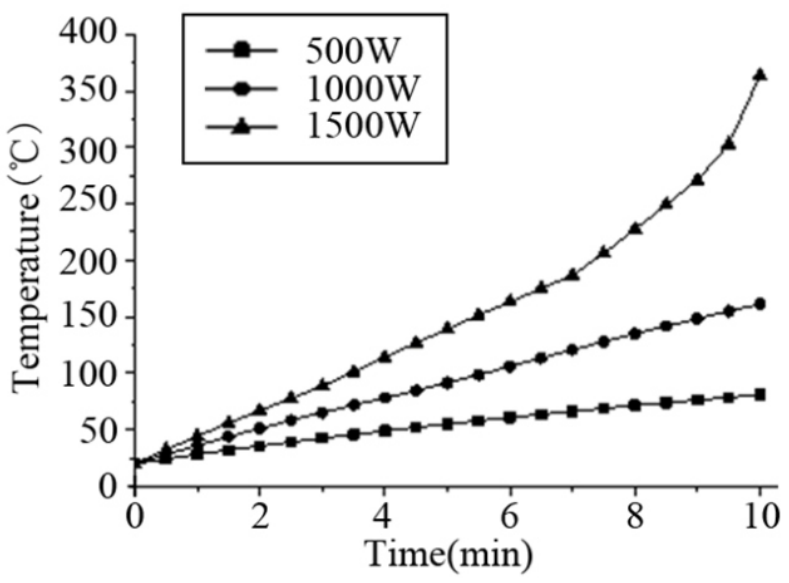

Fig. 4 Center of the surface temperature changes over time with different input power. with 3 (a) and 3 (b), and the area of high temperature is relatively small. The results show that with the increase of microwave power, the temperature difference of samples increases from $6.5{ }^{\circ} \mathrm{C}$ to $115^{\circ} \mathrm{C}$. This phenomenon indicates that increasing the microwave power can greatly raise the temperature of the samples, but it can also lead to the increase of inhomogeneous distribution of temperature. As a whole, the raise of temperature in the entire sample favors the main reaction. Therefore, by changing the mixing mode or adding other thermal conductivity agent can better improve the uniformity of the temperature distribution, so as to further improve the sample recovery of $\mathrm{InCl}_{3}$ as well as the utilization of $\mathrm{HCl}$.

At the same time, the temperature of center in the sample surface changes with different microwave input power (Fig. 4). It can be seen that when at power $500 \mathrm{~W}$ and $1000 \mathrm{~W}$, the temperature of the center point has linearly increased. At input power $1500 \mathrm{~W}$, it tends to be quadratic increase from " $7 \mathrm{~min}$ ", which is because the relative dielectric constant of the sample changes with temperature, and it has reached a critical point in the vicinity of $7 \mathrm{~min}$ leading to the significant temperature rise. This phenomenon reflects that a faster reaction rate can be obtained when the overall average temperature of the sample is raised above $200{ }^{\circ} \mathrm{C}$.

Meanwhile, it can be observed from Fig. 5 that the distribution trend of $\mathrm{InCl}_{3}$ concentration is basically the same at different input power, which shows that the diffusion of the existing reaction system and the convective material transmission have an excellent effect and do not restrict the progress of the current chemical reaction. Secondly, the maximum concentration of $\mathrm{InCl}_{3}$ is $1.6 \mathrm{~mol} / \mathrm{m}^{3}$ at power $500 \mathrm{~W}$, while it is $5.77 \mathrm{~mol} / \mathrm{m}^{3}$ at power $1000 \mathrm{~W}$. At power $1500 \mathrm{~W}$, the maximum concentration of $\mathrm{InCl}_{3}$ increases to $40.7 \mathrm{~mol} / \mathrm{m}^{3}$. This phenomenon also proves that when the temperature reaches the critical point of relative permittivity, the reaction rate can be greatly improved.

4.2 The impact of the quartz tube's position on temperature rise Due to the fact that the distribution of the electric field in the microwave cavity is not completely uniform, the sample position will

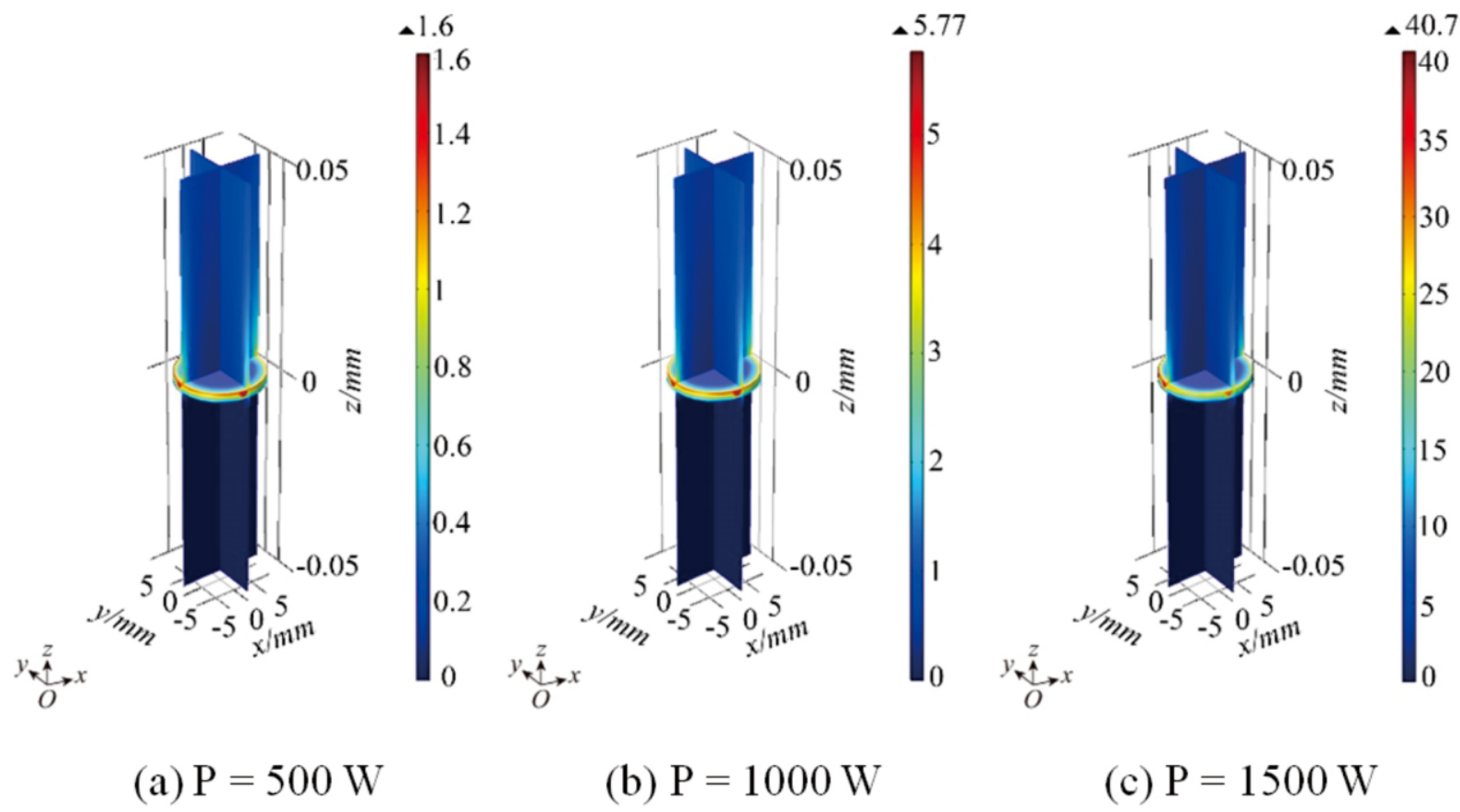

Fig. 5 Concentration distributions of $\mathrm{InCl}_{3}$ in the quartz tube of heating $10 \mathrm{~min}$. 
change with the quartz tube's position. First, place the quartz tube in the center of the microwave cavity and observe the electric field distribution in the cavity, Fig. 6 (a). Observe the changes of the field intensity based on the translation of the quartz tube in the $\mathrm{x}, \mathrm{y}$ direction. When $\Delta \mathrm{x}$ is 25, $\Delta \mathrm{y}$ is -20 , it is shown in Fig. 6 (b).

Seeing from Fig. 6 (a), when the quartz tube cavity is in the center position, the electric field intensity is smaller at this moment. According to the formula of microwave heat source, the rise rate of temperature and the amplitude will increase under larger field intensities. Place the quartz tube in the microwave cavity with larger field intensity by the translation in the $\mathrm{x}, \mathrm{y}$ direction. When $\Delta \mathrm{x}$ is 25 and $\Delta y$ is -20 , the maximum value of field intensity in the tube increases from $7 \times 10^{4} \mathrm{~V} / \mathrm{m}$ at the center to $1 \times 10^{5} \mathrm{~V} / \mathrm{m}$. The maximum values of field intensity are obtained at the sample surface, which is caused by the skin effect. The field intensity distribution in Fig. 6 shows that the overall distribution of the interior cavity has not changed, but the field intensity at the sample has been increased by about $43 \%$.

After transferring the quartz tube to a new position, the temperature distribution of the sample heated for $6 \mathrm{~s}$ is shown in Fig. 7. It can be clearly observed that the temperature rise rate of the quartz tube has been greatly improved in the new position, but the temperature difference of the sample also exceeds $500{ }^{\circ} \mathrm{C}$. It also indicates that the reasonable sample position can effectively reduce the microwave input power so as to save energy and reduce the cost of the process.

\subsection{The impact of HCI flow on mass transfer}

The change of hydrodynamic flow velocity has certain influence on the convective heat transfer and convection mass transfer in the quartz tube.

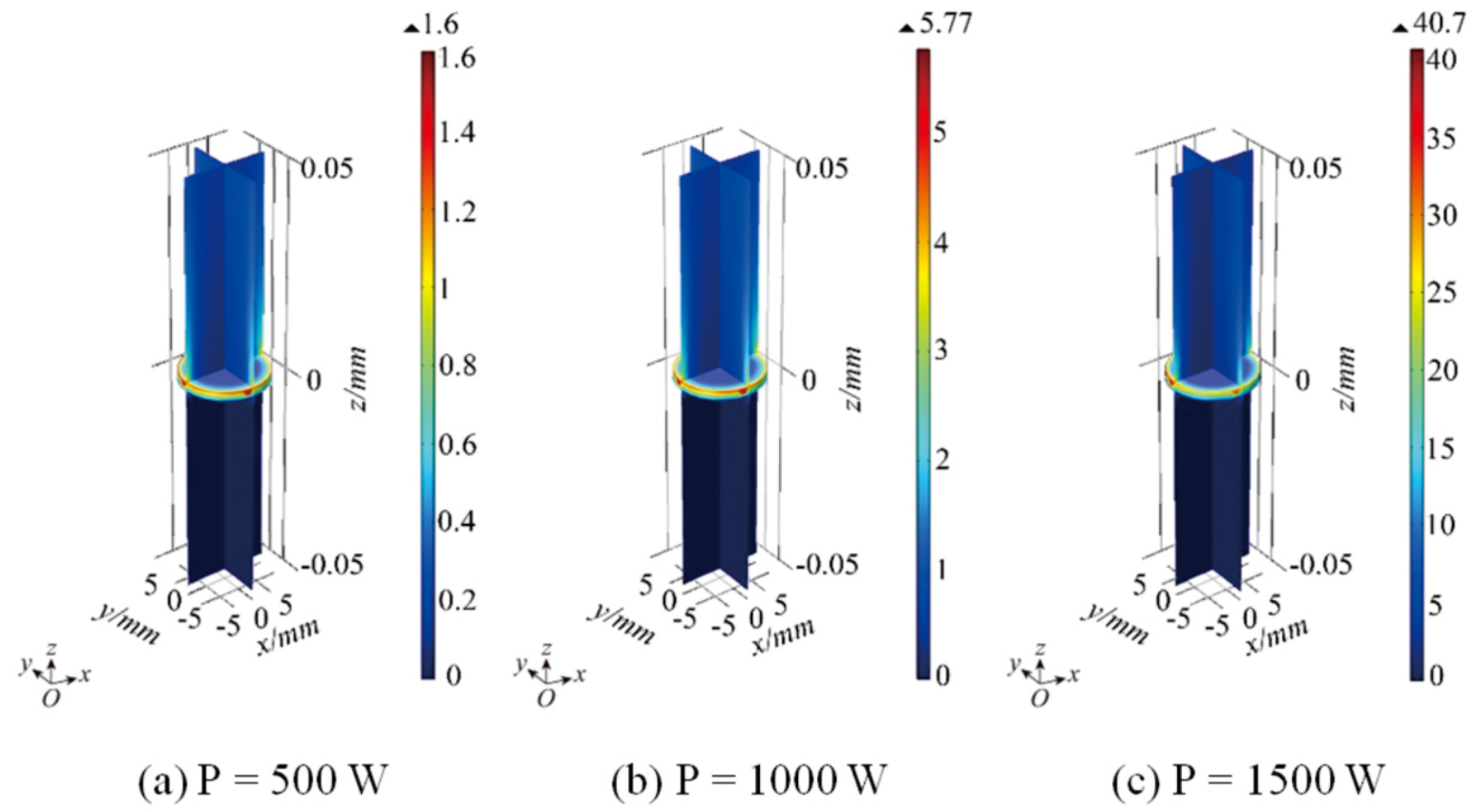

Fig. 5 Concentration distributions of $\mathrm{InCl}_{3}$ in the quartz tube of heating $10 \mathrm{~min}$.

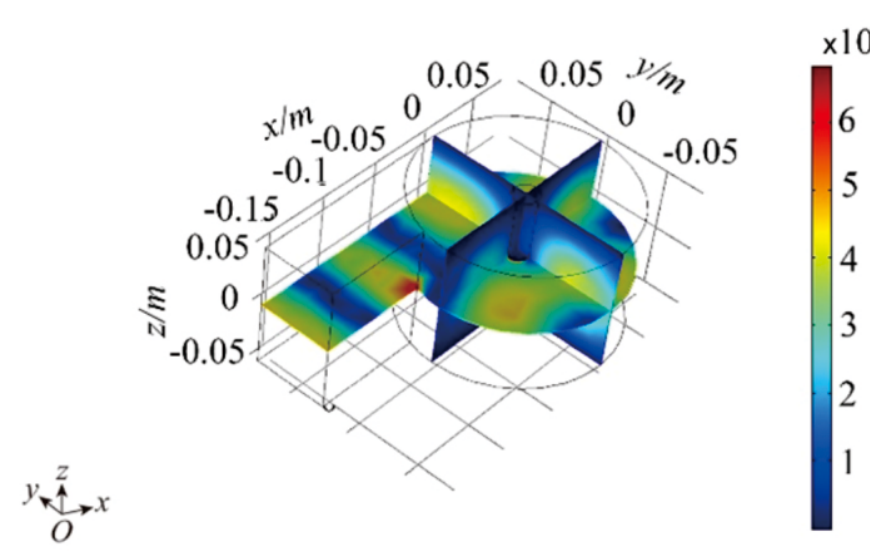

(a) Tube is placed at the center of the cavity

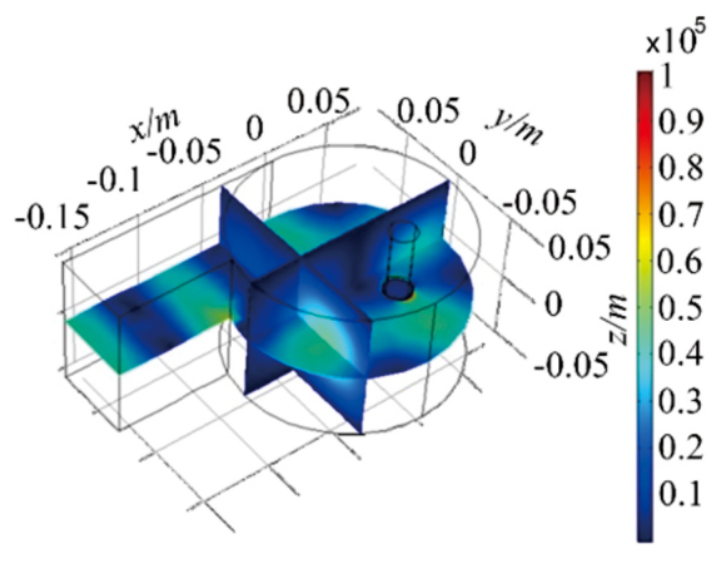

(b) Tube is placed at the higher electric field of the cavity

Fig. 6 Field intensity distributions at different position of the quartz tube. 


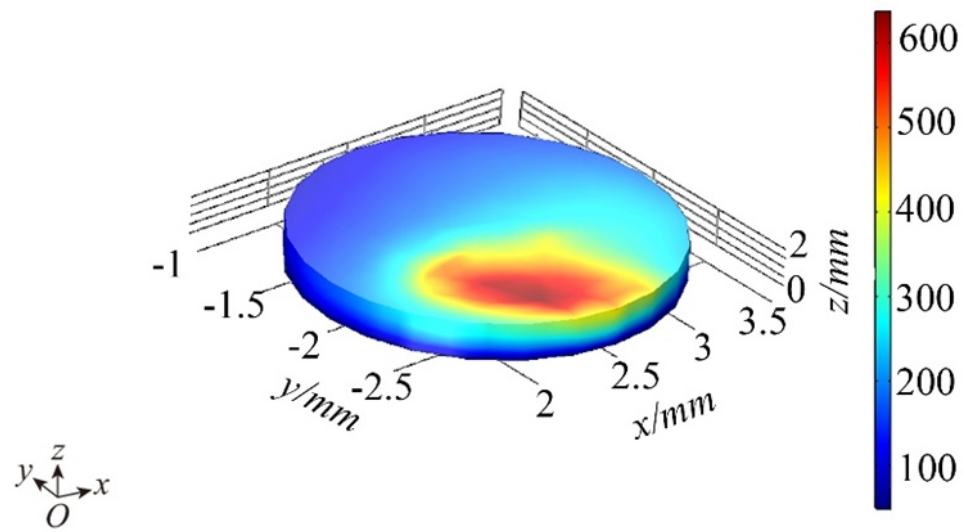

Fig. 7 Temperature distribution of heating $6 \mathrm{~s}$ in the new position.

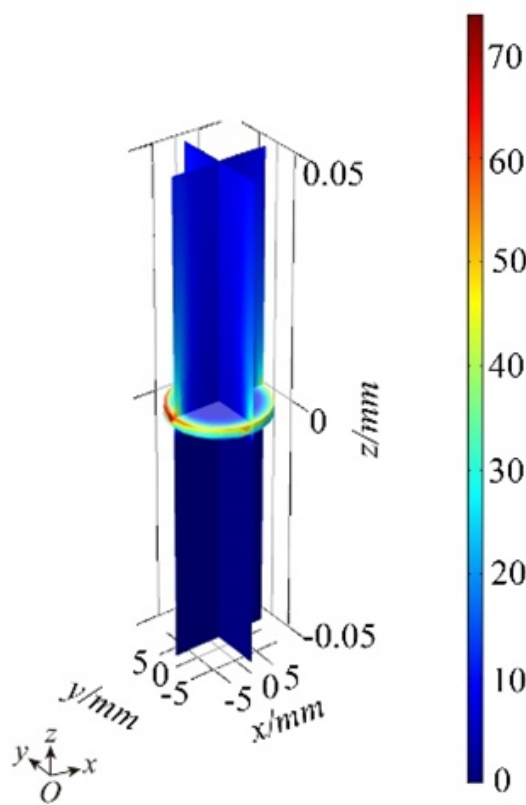

(a) $\mathrm{Q}_{\mathrm{HCl}}=50 \mathrm{ml} / \mathrm{min}$

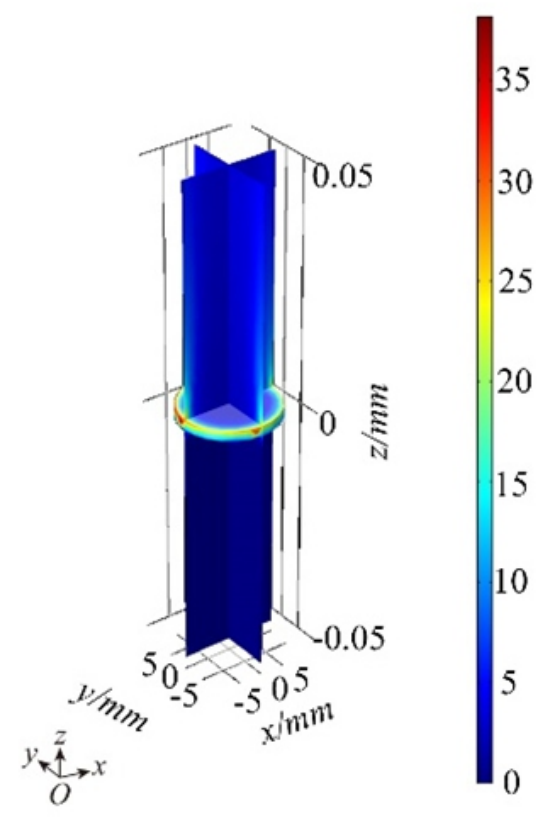

(b) $\mathrm{Q}_{\mathrm{HCl}}=100 \mathrm{ml} / \mathrm{min}$

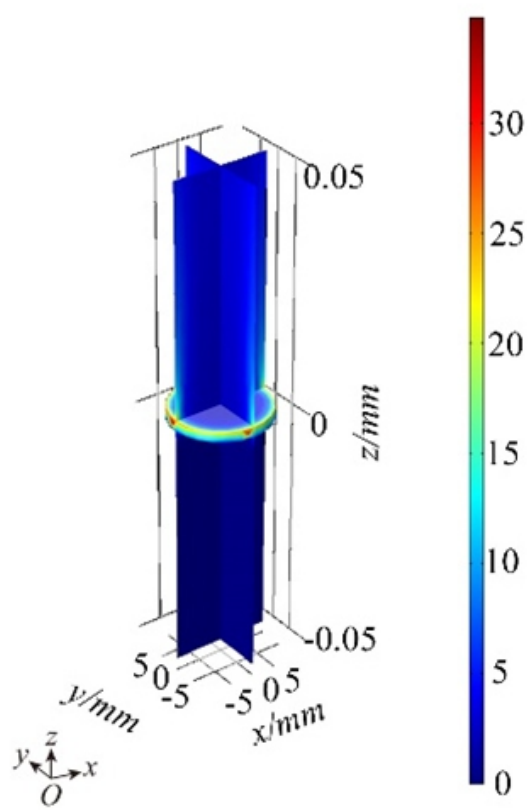

(c) $\mathrm{Q}_{\mathrm{HCl}}=150 \mathrm{ml} / \mathrm{min}$

Fig. $8 \mathrm{InCl}_{3}$ concentration distributions at different $\mathrm{HCl}$ flow.

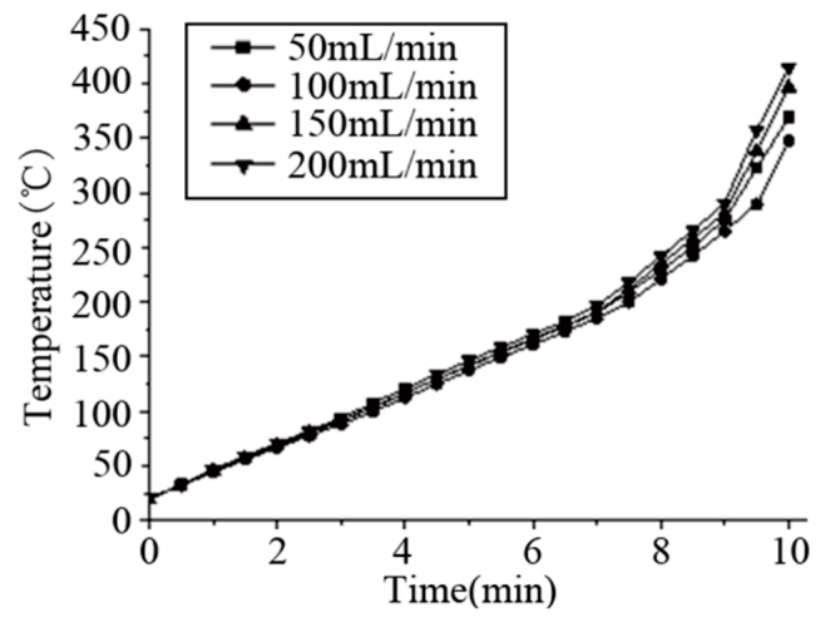

Fig. 9 Center of the surface temperature changes over time with different $\mathrm{Q}_{\mathrm{HCl}}$ 
In the view of energy transmission, a larger flow rate can improve the overall heat and material transmission in the system. By changing the flow of $\mathrm{HCl}$ gas, the corresponding concentration distribution of $\mathrm{InCl}_{3}$ can be obtained when the $\mathrm{Q}_{\mathrm{HCl}}$ is $50 \mathrm{ml} / \mathrm{min}, 100 \mathrm{ml} / \mathrm{min}$ and 150 $\mathrm{ml} / \mathrm{min}$ (Fig. 8).

The results shows that as the flow of $\mathrm{HCl}$ increased, the concentration of $\mathrm{InCl}_{3}$ in the tube gradually decreased from $70 \mathrm{~mol} / \mathrm{m}^{3}$ to $35 \mathrm{~mol} / \mathrm{m}^{3}$, which indicates that the larger velocity can enhance the mass transfer effect in the system, but it may also cause the risk of low utilization of the reactant.

The change of $\mathrm{HCl}$ flow $\left(\mathrm{Q}_{\mathrm{HCl}}\right.$ is $50 \mathrm{ml} / \mathrm{min}, 100 \mathrm{ml} / \mathrm{min}, 150$ $\mathrm{ml} / \mathrm{min}, 200 \mathrm{ml} / \mathrm{min}$ ) can make out the temperature variation on the center point of sample surface with time, as shown in Fig. 9. The results show that the effect of $\mathrm{HCl}$ flow on the surface temperature of the sample improves with the increased heating time. It proves that as the temperature rises, the main reaction becomes more intense, and it further adds the difference in heat transfer for flow velocity. It should be pointed out that when $\mathrm{Q}_{\mathrm{HCl}}$ is $50 \mathrm{ml} / \mathrm{min}$, the temperature rise effect on the center point of sample surface is greater than that in $\mathrm{Q}_{\mathrm{HCl}} 100 \mathrm{ml} /$ min. This trend shows that the impact of flow rate on the heat transfer can be divided into two aspects. First, the flow rate can speed up heat exchange of the sample with the external medium. Second, at a certain flow rate, the lower flow rate is more conducive to sufficient heat exchange of the sample. By comparing the influence of different $\mathrm{HCl}$ flow conditions on the temperature rise curve at the center of the sample surface, we can consider that the dominant temperature of the sample is the microwave heat source, followed by the convection mass transfer.

\section{Conclusions and outlook}

Based on COMSOL Multiphysics, coupled model in multi-physics fields of RF-temperature rise-fluid-chemical reaction is established and the effect of electromagnetic heat flux in coupling reaction on the recovery of indium by microwave carbothermal chlorination approach is studied. The main conclusions are as follows:

a) The full coupling analysis of electromagnetic-temperature-flowchemical reaction can be realized in the COMSOL Multiphysics model and can be used to study the coupling impact of the variables;

b) During the heating process, the heat source of microwave radiation is the main reason for the change of sample temperature, followed by the convective heat transfer. Therefore, it is of great significance to study the microwave heating process on the reaction of indium chloride;

c) Appropriate microwave cavity design and sample location have a significant impact on the heating rate and energy saving in the indium recovery process, and enjoys a large space for optimization.

\section{Acknowledgments}

We gratefully appreciate the financial support from Natural Science Foundation of China (51678353), Cultivate discipline fund of Shanghai Polytechnic University (XXKPY1601) and Eastern Scholar Professorship Grant. The authors also acknowledge the Graduate Student Funding Program of Shanghai Polytechnic University, The Shanghai Youth Science and Technology Talent Sailing Plan(17YF1425600), The Special Found for Basic Business Expenses of Public Welfare Research Institutes at the Central Level(2016T10) and Gaoyuan Discipline of Shanghai-Environmental Science and Engineering (Resource Recycling Science and Engineering).

\section{References}

1. L. Zhang, B. Wu, Y. Chen and Z. Xu, J. Clean Prod., 2017, 162, 141-152.

2. Y. He, E. Ma and Z. Xu, J. Hazard. Mater., 2014, 268, 185-190.

3. M. Frenzel, T. Hirsch and J. Gutzmer, Ore Geol. Rev., 2016, 76, 52-78.

4. F. Zhang, C. Wei, Z. Deng, X. Li, C. Li and M. Li, Hydrometallurgy, 2016, 161, 102-106

5. G. Dodbiba, H. Nagai, L. P. Wang, K. Okaya and T. Fujita, Waste Manag., 2012, 32, 1937-1944.

6. L. Rocchetti, A. Amato, V. Fonti, S. Ubaldini, I. De Michelis, B. Kopacek, F. Vegliò and F. Beolchini, Waste Manag., 2015, 42, 180-187.

7. L. Rocchetti, A. Amato and F. Beolchini, J. Clean Prod., 2016, 116, 299-305.

8. Matsumoto, Katsutoshi, S. Taniguchi, A. Kikuchi, J. Jpn. Inst. Met., 1999, 63, 345-351.

9. J. Li, S. Gao, H. Duan and L. Liu, Waste Manag., 2009, 29, 2033-2039.

10. J. L. Ruan, J. Guo, Y. Qiao, Proced. Environ. Sci., 2012, 16, 545-551.

11. A. V. M. Silveira, M. S. Fuchs, D. K. Pinheiro, E. H. Tanabe and D. A. Bertuol, Waste Manag., 2015, 45, 334-342.

12. X. H. Li, Y. J. Zhang, Q. L. Qin, J. Yang and Y. S. Wei, Trans. Nonferrous Met. Soc. China, 2010, 20, 141-145.

13. M. Martin, E. Janneck, R. Kermer, A. Patzig and S. Reichel, Miner. Eng., 2015, 75, 94-99.

14. L. Zhang, J. Mo, X. Li, L. Pan, X. Liang and G. Wei, Metall. Mater. Trans. B., 2013, 44, 1329-1336.

15. H. Hasegawa, I. M. M. Rahman, Y. Egawa, H. Sawai, Z. A. Begum, T. Maki and S. Mizutani, J. Hazard. Mater, 2013, 254-255, 10-17.

16. J. Guan, S. Wang, H. Ren, Y. Guo, H. Yuan, X. Yan, J. Guo, W. Gu, R. Su, B. Liang, G. Gao, Y. Zhou, J. Xu and Z. Guo, RSC Adv., 2015, 5, 102836102843.

17. Y. Guo, Q. Zhang, X. Lou, H. Liu, J. Wang, J. Guan, X. Xu, X. Zhang, Y. Li, Y. Li, Z. Guo, Eng. Sci., 2018, 4, 65-69.

18. Y. Guo, S. Wang, H. Ren, J. Guan, H. Yuan, R. Su, G. Gao, X. Lou, D. Xiao, W. Gu, X. Mo, Y. Li, Chin. J. Chem. Eng, 2017, 1, 3731-3739. (in Chinese)

19. E. Ma, R. Lu and Z. Xu, Green Chem., 2012, 14, 3395-3401.

20. S. Virolainen, D. Ibana and E. Paatero, Hydrometallurgy, 2011, 107, 56-61.

Publisher's Note Engineered Science Publisher remains neutral with regard to jurisdictional claims in published maps and institutional affiliations. 